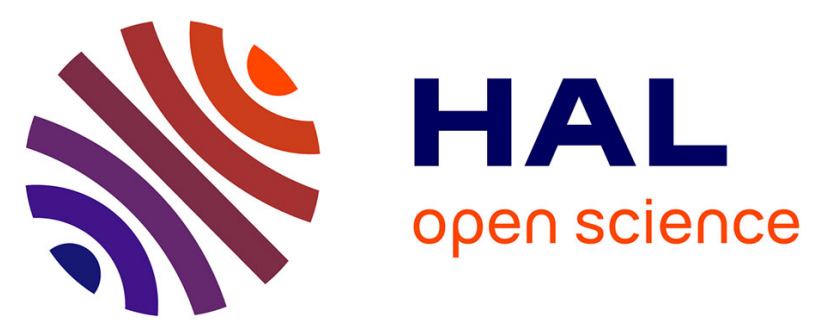

\title{
3d-4f METALLIC COMPOUNDS.Magnetic moment, magnetic anisotropy and spin-reorientation phase transition in (4f-3d)-intermetallic compounds
}

\author{
A. Deryagin
}

\section{To cite this version:}

A. Deryagin. 3d-4f METALLIC COMPOUNDS.Magnetic moment, magnetic anisotropy and spinreorientation phase transition in (4f-3d)-intermetallic compounds. Journal de Physique Colloques, 1979, 40 (C5), pp.C5-165-C5-170. 10.1051/jphyscol:1979562 . jpa-00218979

HAL Id: jpa-00218979

https://hal.science/jpa-00218979

Submitted on 1 Jan 1979

HAL is a multi-disciplinary open access archive for the deposit and dissemination of scientific research documents, whether they are published or not. The documents may come from teaching and research institutions in France or abroad, or from public or private research centers.
L'archive ouverte pluridisciplinaire HAL, est destinée au dépôt et à la diffusion de documents scientifiques de niveau recherche, publiés ou non, émanant des établissements d'enseignement et de recherche français ou étrangers, des laboratoires publics ou privés. 


\title{
3d-4f METALLIC COMPOUNDS.
}

\section{Magnetic moment, magnetic anisotropy and spin-reorientation phase transition in (4f-3d)-intermetallic compounds}

\author{
A. V. Deryagin \\ Ural State University, Sverdlovsk, USSR
}

\begin{abstract}
Résumé. - On analyse le rôle des ions $4 \mathrm{f}$ et $3 \mathrm{~d}$ dans la formation du moment magnétique et de l'anisotropie magnétique dans les composés $4 \mathrm{f}-3 \mathrm{~d}$, ainsi que l'influence des interactions d'échange $4 \mathrm{f}-3 \mathrm{~d}$ entre les sous-réseaux sur la variation thermique du moment magnétique et de l'anisotropie magnétique. On considère les réorientations de spin par transitions de phase spontanées et celles induites par le champ magnétique.
\end{abstract}

Abstract. - The role of $4 \mathrm{f}$ - and $3 \mathrm{~d}$-ions in the formation of magnetic moment and magnetic anisotropy of (4f-3d)-
compounds is discussed as well as the influence of intersublattice ( $4 \mathrm{f}-3 \mathrm{~d}$ )-exchange interaction on their tempe-
rature dependence. Spontaneous and field-induced SR-phase transitions in (4f-3d)-compounds are considered.

1. Introduction. - Great interest in the magnetic properties of intermetallic compounds of $4 \mathrm{f}$-metals (R) with transition $3 \mathrm{~d}$-metals $(\mathrm{T})$ has been displayed in the last 15 years. This is first of all connected with the fact that the (4f-3d)-alloys are used as hard [1] and magnetostrictive [2] magnetic materials, as materials for recording of information using bubble domains [3] as well as for thermomagnetic transducers using spin reorientation [4]. The potential of (4f-3d)compounds for these purposes is determined by such characteristics as spontaneous magnetization, magnetic anisotropy, magnetostriction and Curie temperature. This paper deals with the formation of magnetic moment and magnetic anisotropy in (4f-3d)-compounds as well as spontaneous and field-induced spin reorientation (SR) phase transitions.

2. Magnetic moment of 4 f-ions. - Table I shows the values of the molecular magnetic moment $\left(\mu_{\mathrm{m}}\right)$ at $4.2 \mathrm{~K}$ of $\mathrm{R}_{2} \mathrm{Co}_{17}$ [5], $\mathrm{RCo}_{5}[6,7], \mathrm{R}_{2} \mathrm{Co}_{7}$ [8] monocrystals. Figure 1 gives a comparison of values of the magnetic moment per $4 \mathrm{f}$-ion in a trivalent state $\left(\mu_{f^{3}+}\right)$ calculated from these data by means of the formula

$$
\mu_{\mathrm{f}}=\left(\mu_{\mathrm{m}}^{\mathrm{R}_{\mathrm{m}} \mathrm{Co}_{\mathrm{m}}}-\mu_{\mathrm{m}}^{(Y, L u)_{\mathrm{n}} \mathrm{Co}_{\mathrm{m}}}\right) / \mathrm{n}, \text { with } \mu_{\mathrm{f}}=g J
$$

where $g$ is Lande factor, $J$ is the quantum number of the total angular momentum of $4 \mathrm{f}$-ion. The agreement

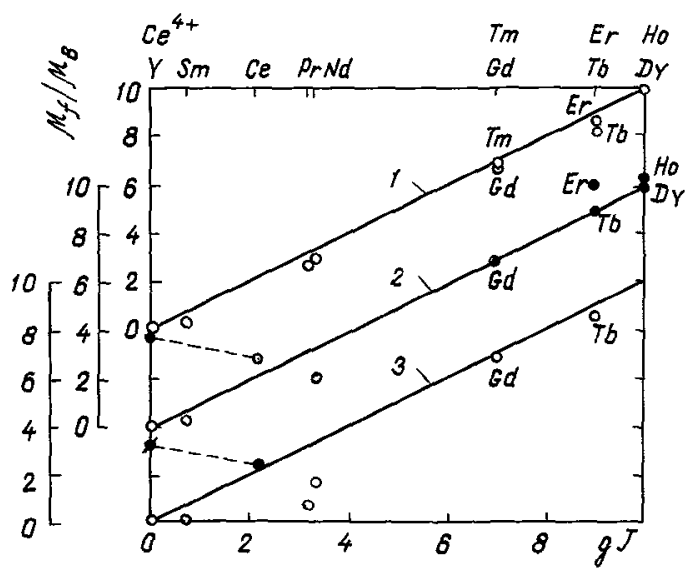

Fig. 1. - $\mu_{\mathrm{f}}$ in $\mathrm{R}_{2} \mathrm{Co}_{17}$ (1), $\mathrm{RCo}_{5}$ (2), $\mathrm{R}_{2} \mathrm{Co}_{7}$ (3) monocrystals vs. $g J$ at $4.2 \mathrm{~K}: 0 \bullet \mathrm{f}^{3+}, \mathrm{f}^{4+} ; \bullet$ Tatsumoto et al. [6].

is not very good, particulary for the light 4 f-ions. However, it may be improved if we take into account the contribution from the polarization of conduction electrons in $\mu_{\mathrm{m}}$ [9] as well as the influence of the crystal and exchange fields on the energy state of $4 \mathrm{f}$-ions. In the case of $\mathrm{Ce}$ compounds it is necessary also to suppose that the $\mathrm{Ce}$ ions are tetravalent and give the additional $4 \mathrm{f}$-electron to the $3 \mathrm{~d}$ Co band, decreasing $\mu_{\mathrm{Co}}$ relative to $\mu_{\mathrm{Co}}$ in $\mathrm{Y}_{\mathrm{n}} \mathrm{Co}_{\mathrm{m}}$ by $\frac{\mathrm{n}}{\mathrm{m}} \mu_{\mathrm{B}}$.

Table I.

\begin{tabular}{|c|c|c|c|c|c|c|c|c|c|c|c|c|}
\hline $\mathbf{R}$ & $\mathrm{Ce}$ & Pr & $\mathrm{Nd}$ & $\mathrm{Sm}$ & Gd & $\mathrm{Tb}$ & Dy & Ho & $\mathrm{Er}$ & $\operatorname{Tm}$ & $\mathrm{Lu}$ & $\mathrm{Y}$ \\
\hline - & - & - & - & - & - & - & - & - & - & - & - & - \\
\hline$\mu_{\mathrm{m}}^{\mathbf{R}_{2} \mathrm{Co}_{17} /} / \mu_{\mathbf{B}}$ & 24.6 & 32.6 & 33.2 & 27.8 & 13.8 & 8.9 & 7.5 & 7.5 & 9.8 & 13.4 & 26.9 & 27.2 \\
\hline$\mu_{\mathrm{m}}^{\mathrm{RCos}} / \mu_{\mathrm{B}}$ & 6.6 & 10.4 & 10.4 & 8.5 & 1.42 & 0.69 & 1.71 & 2.06 & 1.71 & - & - & 8.3 \\
\hline$\mu_{\mathrm{m}}^{\mathbf{R}_{2} \mathrm{Co} 7} / \mu_{\mathrm{B}}$ & - & 10.9 & 13.1 & 9.5 & 4.2 & 7.3 & - & - & - & - & 一 & 9.6 \\
\hline
\end{tabular}


The temperature dependence of the $4 \mathrm{f}$-sublattice magnetic moment for $\mathrm{R}_{2} \mathrm{Co}_{17}$ as shown in figure 2 [5] is approximated by the Brillouin function

$$
\begin{aligned}
\frac{\mu_{\mathrm{R}}(T)}{\mu_{\mathrm{R}}(0)} & =B_{j}\left(\frac{g J \mu_{\mathrm{B}} H_{\mathrm{m}}}{k T}\right)= \\
& =B_{j}\left(\frac{2 A(g-1) J\langle s\rangle}{k T}\right)=B_{j}\left(\frac{\xi_{0} m_{\mathrm{d}}(T)}{T}\right)
\end{aligned}
$$

with a suitable choice of the parameter

$$
\xi_{0}=2 A(g-1) J\langle s\rangle / K .
$$

$\xi_{0}$ represents the magnitude of the (4f-3d)-exchange interaction $\left(H_{\mathrm{m}}\right.$ is the molecular field, $A$ is the resulting exchange parameter, $\langle s\rangle$ is the mean spin value of 3d-ion, $m_{\mathrm{d}}(T)=\mu_{\mathrm{d}}(T) / \mu_{\mathrm{d}}(0)$ is the relative magnetization of the $3 \mathrm{~d}$-sublattice, $k$ is the Boltzmann constant). The value of $\xi_{0}$ for $\mathrm{R}_{2}\left(\mathrm{Co}_{1-x} \mathrm{~T}_{x}\right)_{17}$, where $\mathrm{R}=\mathrm{Sm}, \mathrm{Er}$ and $\mathrm{T}=\mathrm{Fe}, \mathrm{Ni}, \mathrm{Al}$ increases approximately linearly with $\mu_{\mathrm{d}}[10,11]$ as well as with the spin moment of the $4 \mathrm{f}$-ions in $\mathrm{R}_{2} \mathrm{Co}_{17}$ compounds [5].

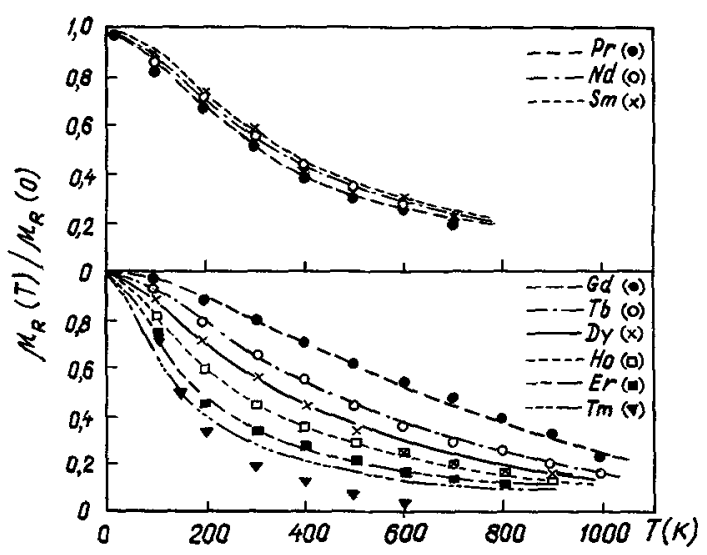

Fig. 2. - Temperature dependences of $4 \mathrm{f}$-sublattice magnetic moment (points-experiment, lines-equation (1)) in $\mathrm{R}_{2} \mathrm{Co}_{17}$.

3. Magnetocrystalline anisotropy. - The magnetic anisotropy of (4f-3d)-compounds may, as a first approximation, be represented as $\mathrm{K}=\mathrm{K}_{\mathrm{f}}+\mathrm{K}_{\mathrm{d}}+\mathrm{K}_{\mathrm{fd}}$. At low temperatures the $4 f$-sublattice anisotropy is dominant. The constancy of the values of the anisotropy coefficients per $\mathrm{Nd}$-ion in $\mathrm{Nd}_{1-x} \mathrm{Y}_{x} \mathrm{Co}_{5}$ when $\mathrm{Nd}$ is substituted by non-magnetic $\mathrm{Y}$, and the small change in lattice parameters $a$ and $c$ (figure 6) points to a single ion type of anisotropy [6]. If the parameters change greatly, $K_{2 \mathrm{Nd}}^{0}$ decreases approximately as the lattice sums in the expression for the crystal field potential. This is clearly seen in the example of the $\mathrm{Nd}_{1-x} \mathrm{U}_{x} \mathrm{Co}_{5}$ compound. Figure 3 shows by solid and dashed lines the dependence

$$
\frac{K_{2 \mathrm{Nd}}^{0}(x)}{K_{2 \mathrm{Nd}}^{0}(0)}=1-3\left[\left(\frac{a(0)}{c(0)}\right)^{3}-\frac{\Delta c(x)}{c(0)}-\right.
$$

$$
\left.-\frac{3}{2} \frac{\Delta a(x)}{a(0)}\right] \cdot\left[\left(\frac{a(0)}{c(0)}\right)^{3}-\frac{3}{2}\right]^{-1}
$$

for $\mathrm{Nd}_{1-x} \mathrm{U}_{x} \mathrm{Co}_{5}$ and $\mathrm{Nd}_{1-x} \mathrm{Y}_{x} \mathrm{Co}_{5}$ [7].

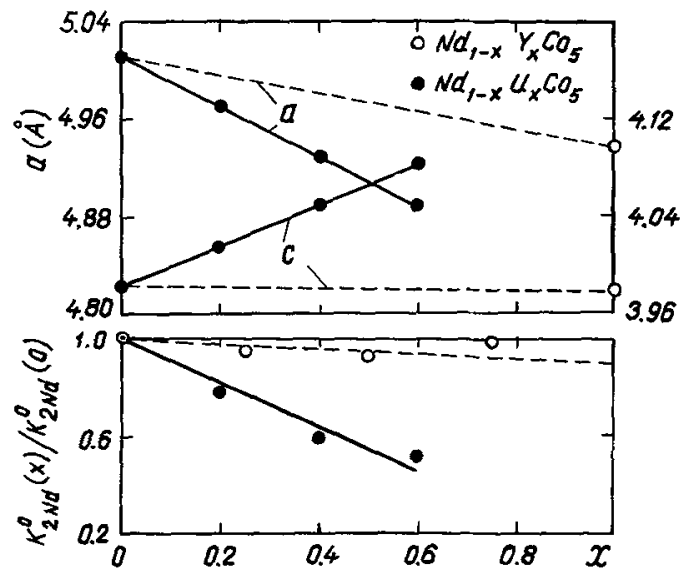

Fig. 3. - See text.

The magnetic anisotropy of (4f-3d)-compounds can be changed in a more subtle way when one 3d-ion is substituted by another. Figure 4 gives as an example the concentration dependence of the anisotropy constants for $\operatorname{Er}_{2}\left(\mathrm{Co}_{1-x} \mathrm{Fe}_{x}\right)_{17}$ [10]. This dependence can be explained if we assume that the anisotropy of these compounds at low temperatures is mainly determined by the Er-sublattice anisotropy, and the crystal field acting on the Er-ions is changed in a complicated way because of an uneven replacement of Co-ions by $\mathrm{Fe}$-ions with unequal charges. In this case we have for $K_{1}^{0}(x)[11,12]$

$$
\begin{aligned}
& K_{1}^{0}(x)=K_{1}^{0}(0)+\omega_{1}\left(q_{\mathrm{Fe}}-q_{\mathrm{Co}}\right) \times \\
& \times\left[\lambda_{\mathrm{d}}^{(1)} \omega_{\mathrm{d}}^{\mathrm{Fe}}+\lambda_{\mathrm{f}}^{(1)} \omega_{\mathrm{f}}^{\mathrm{Fe}}+\lambda_{\mathrm{B}}^{(1)}\left(\frac{17}{2} x-\frac{9}{2} \omega_{\mathrm{d}}^{\mathrm{Fe}}-3 \omega_{\mathrm{f}}^{\mathrm{Fe}}\right)\right],
\end{aligned}
$$

where $\lambda_{\mathrm{d}}^{(1)}, \lambda_{\mathrm{f}}^{(1)}, \lambda_{\mathrm{B}}^{(1)}$ are lattice sums for positions $6 \mathrm{~g}$ and $12 k$ (d-plane), $12 j$ (fd-plane) and $4 \mathrm{f}$ (dumbbell), $\omega_{\mathrm{d}}^{\mathrm{Fe}}$ and $\omega_{\mathrm{f}}^{\mathrm{Fe}}$ are the probabilities of filling lattice sites (at a given $\mathrm{Fe}$ concentration) by $\mathrm{Fe}$ ions in $\mathrm{d}$ - and fd-planes respectively, $q_{\mathrm{Co}}$ and $q_{\mathrm{Fe}}$ are the charges of

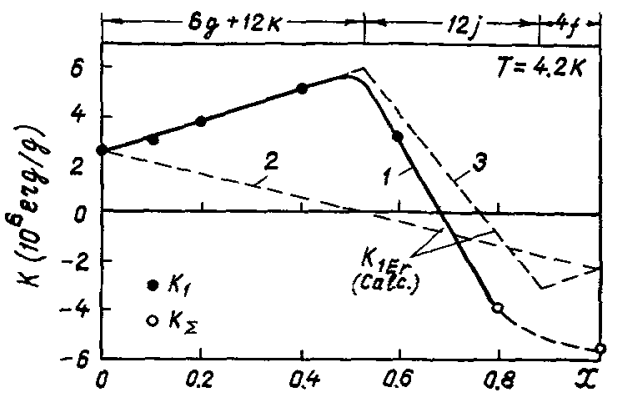

Fig. 4. - Concentration dependence of the magnetic anisotropy of $\mathrm{Er}_{2}\left(\mathrm{Co}_{1-x} \mathrm{Fe}_{x}\right)_{17}(-$ experiment, $\ldots-$ calculation in the case of random substitutions (2), or preferential ordering of $\mathrm{Fe}$ and $\mathrm{Co}(3))$. 
Co and Fe-ions, and $\omega_{1}=-2^{-1+1} e^{2}\left\langle r_{\mathrm{f}}^{1}\right\rangle K_{1}(J)$, where $e$ is the electronic charge, $\left\langle r_{\mathrm{f}}^{1}\right\rangle$ is the mean of the $4 \mathrm{f}$-electronic shell radius in $l$-th power, $K_{1}(J)=\alpha_{\mathrm{i}} 0_{1}^{0} \quad\left(\alpha_{\mathrm{i}}\right.$ and $0_{1}^{0}$ are respectively ElliottStevens parameters and operators). Taking into consideration that values and signs of lattice sums are different for different sites of the $\mathrm{Th}_{2} \mathrm{Ni}_{17}$ type structure, one can generally speaking obtain theoretically different $K_{1}^{0}(x)$ values depending on the preferential filling of the lattice sites by Fe-ions and on the different values of the ionic charges. The best agreement of the experimental $K(x)$ dependence with the theoretical one $K_{1}^{0}(x)$ is obtained by assuming that the Fe-ions occupy the sites in the following sequence $6 g+12 k, 12 j, 4 f$ and that $q_{\mathrm{Co}}=0, q_{\mathrm{Fe}}=0.7 q_{\mathrm{Er}}$ (figure 4).

The temperature dependence of anisotropy constants for $\mathrm{R}_{2} \mathrm{Co}_{17}$ are shown in figures 5 and 6 [5]. From these data for compounds with the light $4 \mathrm{f}$ ions we determined $K_{1}^{0}(T)$ for the 4 f-sublattice and compared them (figure $8 b$ ) with the theoretical ones using a model of crystal field single-ion anisotropy

$$
\begin{aligned}
K_{1}^{0}(T) / K_{1}^{0}(0) & =\hat{I}_{1+1 / 2}\left[\mathfrak{L}^{-1}\left(\mu_{\mathrm{R}}(T) / \mu_{\mathrm{R}}(0)\right)\right] \\
& =\mathfrak{L}_{1}^{J}\left[\mu_{\mathrm{R}}(T) / \mu_{\mathrm{R}}(0)\right],
\end{aligned}
$$

where $\mathfrak{L}_{1}^{J}$ depends on $\xi_{0}$ and is tabulated in [13]. The agreement between the experimental and calculated $K_{1}^{0}(T)$ is very good, if we take $\xi_{0}$ from [5]. Similar results were obtained by us for $\mathrm{NdCo}_{5}$ [7]. Thus, by changing $\xi_{0}$, e.g. changing $\mu_{\mathrm{d}}$, we can vary the temperature dependence of the magnetic anisotropy of the $4 \mathrm{f}$-sublattice and, therefore, that of the (4f-3d)-compound as a whole [11].

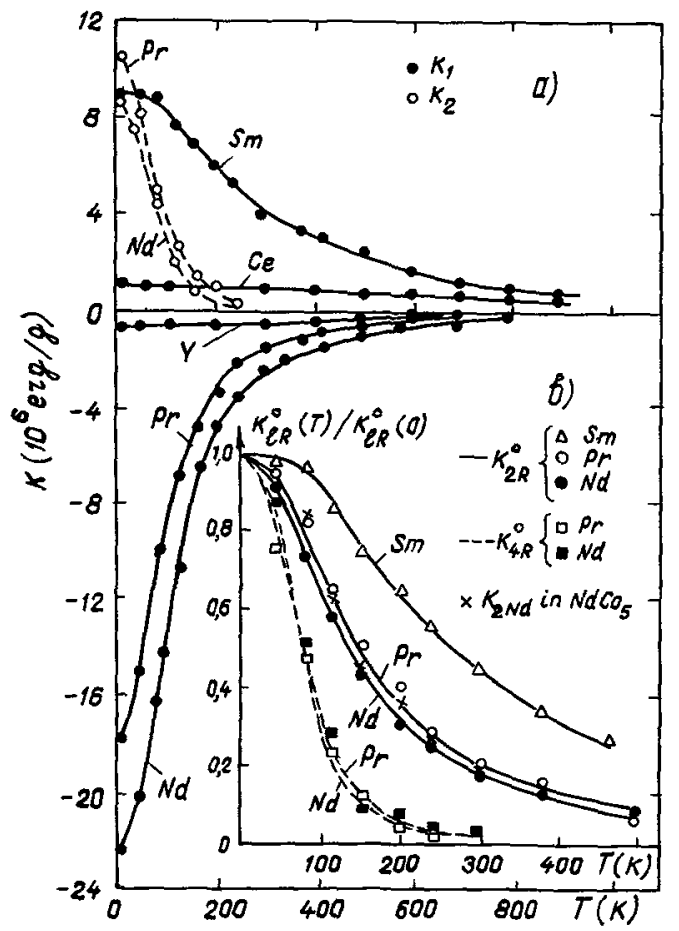

Fig. 5. - $-a) K_{1}$ and $K_{2}$ vs. $T$ in $\mathrm{R}_{2} \mathrm{Co}_{17}$ compounds; $b$ ) $K_{\mathrm{IR}}^{0}(T) / K_{\mathrm{IR}}^{0}(0)$ vs. $T$ (points-experiment, lines-calculation on Eq. (4)).

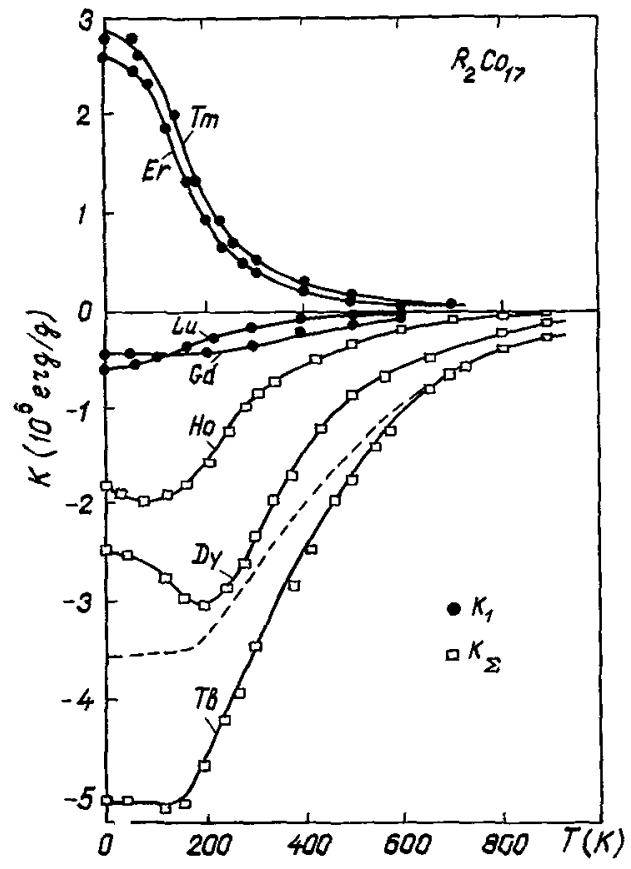

Fig. 6. $-K_{1}$ and $K_{\Sigma}=K_{1}+2 K_{2}+\cdots+v s$. $T$ of $\mathrm{R}_{2} \mathrm{Co}_{17}$ compounds (-.. calculation [5])

For $\mathrm{R}_{2} \mathrm{Co}_{17}$ with heavy $4 \mathrm{f}$-ions the $K(T)$ is more complex especially for $\mathrm{Tb}_{2} \mathrm{Co}_{17}, \mathrm{Dy}_{2} \mathrm{Co}_{17}$ and $\mathrm{Ho}_{2} \mathrm{CO}_{17}$ (figure 6). This is probably connected with the fact that a non-collinear magnetization can appear along the hard direction and give an additional increase of the magnetization $[14,15]$. Taking into consideration this effect, we theoretically obtained the temperature dependence of the effective anisotropy constant for $\mathrm{Tb}_{2} \mathrm{Co}_{17}$ (dashed line) in agreement with the experimental $K_{\varepsilon}(T)$, as well as the temperature dependence of the true anisotropy constant of the $4 \mathrm{f}$-sublattice [5].

The $K_{1}(T)$ of the Co-sublattice in (4f-Co)-compounds is satisfactorily defined by the Akulov-ZinerCarr law [16]

$$
K_{1}(T) / K_{1}(0)=\left(1-\alpha T / T_{\mathrm{c}}\right)\left[\sigma_{s}(T) / \sigma_{s}(0)\right]^{3}
$$

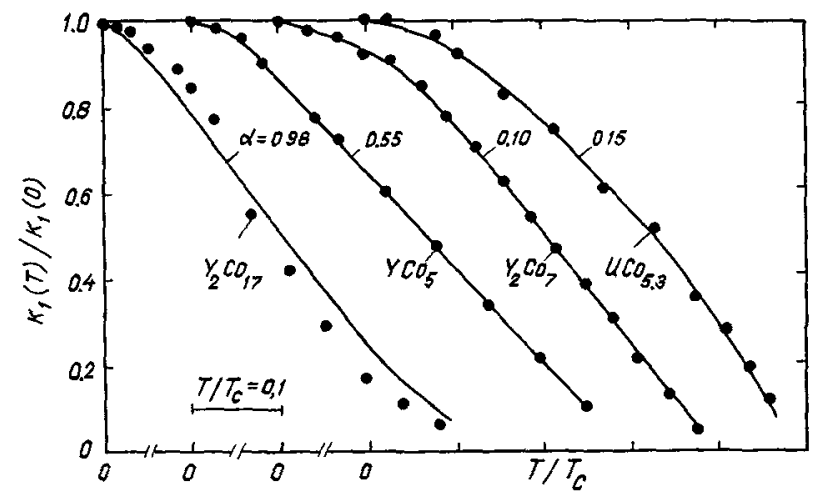

Fig. 7. - K $K_{1}$ vs. Tof $\mathrm{Y}_{2} \mathrm{Co}_{17}, \mathrm{YCo}_{5}, \mathrm{Y}_{2} \mathrm{Co}_{7}, \mathrm{UCo}_{5.3}$ (experiment, - calculation on Eq. (5)). $\mathrm{YCo}_{5}$ Frederick et al. [17] 
with a suitable choice of the coefficient $\alpha$, as shown in figure 7.

4. Spin reorientation phase transitions. - A detailed review of the studies concerning this problem was recently given by K. P. Belov et al. [18]. Here we shall only give some examples of such phase transitions in (4f-3d)-compounds. Figure 8 shows the temperature dependence of the angle $\varphi$ between the $c$-axis and the direction of magnetization in $\mathrm{Nd}_{1-x} \mathrm{U}_{x} \mathrm{Co}_{5}$ monocrystals [7]. When $T$ increases from $T_{1}$, the angle $\varphi$ gradually decreases and when $T \geqslant T_{2}$ the magnetization lies in the basal plane of the lattice. At such SR-transitions the magnitude of $\mu_{\mathrm{f}}$ is preserved, as shown in [19] for $\mathrm{TbCo}_{5}$. The angle $\varphi$ is determined by the equation $\varphi=\arcsin \left(-K_{1} / 2 K_{2}\right)^{1 / 2}$ which is experimentally confirmed for these phase transitions of the second type $\left(K_{2}>0\right)$ accompanied by heat capacity anomalies [20]. Changing $K_{1}(T) / K_{2}(T)$ by change of the uranium concentration, it is possible to shift the temperature of the SR-transitions in $\mathrm{Nd}_{1-x} \mathrm{U}_{x} \mathrm{Co}_{5}$. This latter fact will be of practical importance, if the (4f-3d)-compounds with such transitions really find application in thermomagnetic transducers.

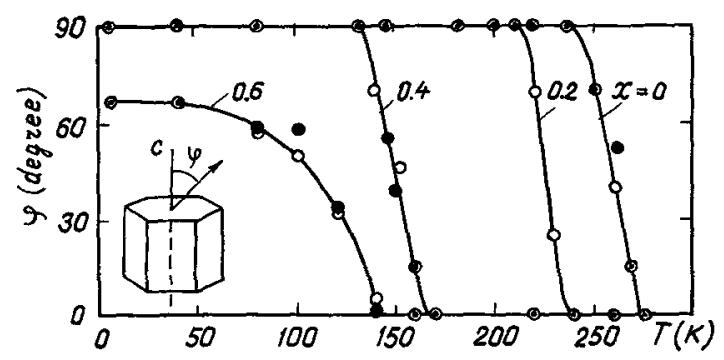

Fig. 8. $-\varphi$ vs. $T$ for $\mathrm{Nd}_{1-x} \mathrm{U}_{x} \mathrm{Co}_{5}$ monocrystals (O from the measurement on torque magnetometer,

$$
\text { - } \left.-\varphi=\arcsin \sqrt{\left(-K_{1} / 2 K_{2}\right)}[7]\right) \text {. }
$$

An another example of SR-transitions are those occurring when magnetizing materials with certain relations between $K_{1}$ and $K_{2}$. A theoretical analysis is given in [21-23]. In the case of easy-axis materials with $H$ applied perpendicular to this axis there exists a field $H_{\mathrm{k}}$ at which the magnetization of a singledomain increases in a jump from $m_{\mathrm{k}}=\sigma_{\mathrm{k}} / \sigma_{\mathrm{s}}$ to 1 , if $-1 \leqslant K_{2} / K_{1} \leqslant-1 / 6$ (see insert in figure 9), where

$$
\begin{aligned}
& H_{\mathrm{k}}=4 K_{1}\left(-K_{1} / K_{2}\right)^{1 / 2} / 3 \sqrt{6} \sigma_{\mathrm{s}} \quad \text { (a) } \\
& m_{\mathrm{k}}=\left(-K_{1} / 6 K_{2}\right)^{1 / 2} \quad \text { (b) }
\end{aligned}
$$

When decreasing $H$, the saturated state becomes absolutely unstable at a field

$$
H_{\mathrm{k}}^{\prime}=2\left(K_{1}+2 K_{2}\right) / \sigma_{\mathrm{s}} \text {. }
$$

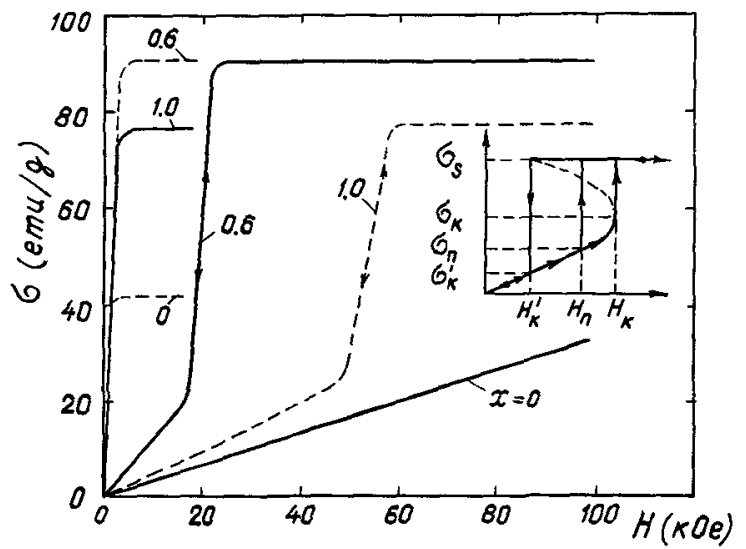

Fig. 9. $-\sigma v$ s. applied field $H$ in $\mathrm{Er}_{2}\left(\mathrm{Co}_{1-x} \mathrm{Fe}_{x}\right)_{17}$ monocrystals at $4.2 \mathrm{~K}: \ldots-H \| c,-H \perp c$.

As we see, an hysteresis $\Delta H=H_{\mathrm{k}}-H_{\mathrm{k}}^{\prime}$ takes place in this phase transition of first order. If at $H=0$ the material exhibits a domain structure, during magnetization a nuclei of a new magnetic phase with magnetization parallel to the basal plane is formed in a field $H_{\mathrm{n}}<H_{\mathrm{k}}$ at $m_{\mathrm{n}}=\sigma_{\mathrm{n}} / \sigma_{\mathrm{s}}$, where

$$
\begin{array}{ll}
H_{\mathrm{n}}=\left(2 K_{1} / \sigma_{\mathrm{s}}\right) m_{\mathrm{n}}+\left(4 K_{2} / \sigma_{\mathrm{s}}\right) m_{\mathrm{n}}^{3} & \text { (a) ; } \\
m_{\mathrm{n}}=\frac{1}{3}\left[\left(\frac{-3 K_{1}}{K_{2}}-2\right)^{1 / 2}-1\right] & \text { (b) } ;
\end{array}
$$

The transition during magnetization of an easyplane material along the $c$-axis, with $4 K_{2}-K_{1} \leqslant 0$, may occur in a similar way. In this case the corresponding transition parameters are

$$
\begin{aligned}
& H_{\mathrm{k}}=-\frac{4\left(K_{1}+2 K_{2}\right)}{3 \sigma_{\mathrm{s}}}\left(\frac{1}{3}-\frac{1}{6} \frac{K_{1}}{K_{2}}\right)^{1 / 2} \quad \text { (a) } ; \\
& m_{\mathrm{k}}=\left(\frac{K_{1}+2 K_{2}}{6 K_{2}}\right)^{1 / 2} \quad(\mathrm{~b}) ; \\
& H_{\mathrm{k}}^{\prime}=-2 K_{1} / \sigma_{\mathrm{s}} \\
& H_{\mathrm{n}}=\frac{2\left(2 K_{2}-K_{1}\right)}{\sigma_{\mathrm{s}}} m_{\mathrm{n}}+\frac{4 K_{2}}{\sigma_{\mathrm{s}}} m_{\mathrm{n}}^{3} \quad \text { (a); } \\
& m_{\mathrm{n}}=\frac{1}{3}\left[\left(\frac{3 K_{1}}{K_{2}}+4\right)^{1 / 2}-1\right] \quad \text { (b); }
\end{aligned}
$$

Experiments showing the possibility of such transitions are given in [23] for $\mathrm{Pr}_{2}\left(\mathrm{Co}_{1-x} \mathrm{Fe}_{x}\right)_{17}$ and in figure 9 for $\operatorname{Er}_{2}\left(\mathrm{Co}_{1-x} \mathrm{Fe}_{x}\right)_{17}$. In the uniaxial case $(x=0,6)$ one obtains from figure 9

$$
H_{\mathrm{a}}=\frac{2 K_{1}}{\sigma_{\mathrm{s}}}=72 \mathrm{kOe}, \quad m_{\mathrm{n}}=0.23 .
$$

From Eq. $(7 a, b)$ we obtain $H_{\mathrm{k}}=24.1 \mathrm{kOe}$ and $H_{\mathrm{n}}=15.7 \mathrm{kOe}$, which is close to the experimental value $17.5 \mathrm{kOe}$. Thus we can assume that the SRphase transitions occurs by the shift of domain walls, 
in agreement with the fact that $\frac{\mathrm{d} \sigma}{\mathrm{d} H} /_{H \approx H_{n}}$ is approximately equal to the demagnetizing factor of the sample $N$ (in our case $N=4 \pi / 3$ ). We did not find any hysteresis (within an accuracy of about $100 \mathrm{Oe}$ ) which is, probably, connected with the easy formation of a transitional domain structure on crystal defects when $H$ is decreased and with small pinning of domain walls on lattice defects.

In case of easy plane type anisotropy $(x=1.0)$ we have, from figure 9

$$
H_{\mathrm{a}}=2\left(K_{1}+2 K_{2}\right) / \sigma_{\mathrm{s}}=154 \mathrm{kOe} \text { and } m_{\mathrm{n}}=0.31 \text {. }
$$

From Eqs. (8), (10) we obtain $H_{\mathrm{k}}=61 \mathrm{kOe}$ and $H_{\mathrm{n}}=57 \mathrm{kOe}$ which is also close to the experimental value of $48 \mathrm{kOe}$.

Interesting examples of SR-phase transitions observed in the (4f-3d)-compounds are the fieldinduced (metamagnetic) phase transitions, where the type of magnetic ordering is changed. Figure 10 shows the magnetization curves of a $\mathrm{Gd}_{3} \mathrm{Co}$ monocrystal at $T=8 \mathrm{~K}$ along the $a-, b-, c$-axes [24]. This compound is a noncollinear antiferromagnet with a magnetic structure of a cross-type, the $\mathrm{Gd}$ magnetic moments (Co has no magnetic moment) lying in the $b c$-plane of the $\mathrm{Fe}_{3} \mathrm{C}$ type lattice [25].

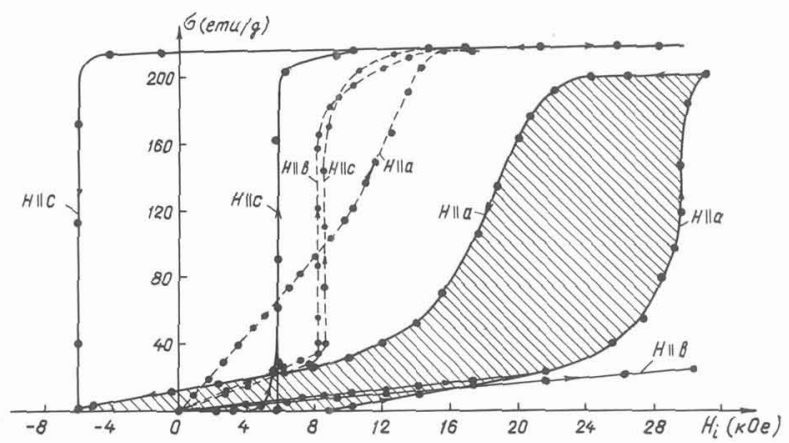

Fig. 10. - $\sigma$ vs. internal field $H_{\mathrm{i}}$ for monocrystals of $\mathrm{Gd}_{3} \mathrm{Co}$ (- - - -) and $\left(\mathrm{Gd}_{0.2} \mathrm{~Tb}_{0.8}\right)_{3} \mathrm{Co}(--)$ at $8 \mathrm{~K}$ along different crystallografic directions. (Each point was measured $30 \mathrm{~s}$ after application of the field.)
When $H$ is increased along the $b$-and $c$-axes $\sigma$ increases linearly at first, at $H_{\mathrm{k}}=8.1-8.4 \mathrm{kOe}, \sigma$ rises in a jump to $\sigma_{\mathrm{k}}=0.73 \sigma_{\mathrm{s}}$ and then increases gradually to $\sigma_{s} \cdot \mu_{\mathrm{Gd}}$ being equal to $g J$ that shows the ordering of $\mu_{\mathrm{Gd}}$ in the state of magnetic saturation to be ferromagnetic.

When $H$ is decreased, we observe an hysteresis $\Delta H=300 \mathrm{Oe}$ in the steepest part of $\sigma\left(H_{\mathrm{i}}\right)$ (not shown in figure 10). Thus we see that the phase transition is of the first type. Noting that $\left.\frac{\mathrm{d} \sigma}{\mathrm{d} H}\right|_{H \approx H_{\mathrm{k}}}=\mathcal{N}$ we may conclude that the transition, as in the previous case, occurs by moving of the metamagnetic walls [26]. When defects are introduced in the crystal the phase transition is field spread [24]. This shows that walls can be nucleated near the crystal defects.

$\Delta H$ is considerably increased if we increase the magnetic anisotropy, as seen in the example of the isostructural compound $\left(\mathrm{Gd}_{0.2} \mathrm{~Tb}_{0.8}\right)_{3} \mathrm{Co}[1,27]$. This compound has a noncoplanar magnetic structure with a ferromagnetic component along the $c$-axis and an antiferromagnetic one along the $a$ - and $b$-axes similar to the structure of $\mathrm{Tb}_{3} \mathrm{Co}$ [28]. Noting that $\left.\frac{\mathrm{d} \sigma}{\mathrm{d} \mathrm{H}}\right|_{H \approx H_{\mathrm{k}}}=\mathcal{N}$ holds here as well, we may assume that the AF-F phase transition occurs by motion of the metamagnetic walls. Since this compound has a value of magnetic anisotropy $\left(\sim 10^{8} \mathrm{erg} / \mathrm{cm}^{3}\right)$ comparable with the exchange energy, the walls are narrow (several inter-atomic parameters). As we known, such walls have a high intrinsing coercivity [29]. This fact explains in our opinion the high magnetic hysteresis in the AF-F transition. At a proper choice of fundamental magnetic characteristics $\mathrm{K}$ and $\mathrm{A}$, hysteresis may be so large $\left(\Delta H>H_{\mathrm{k}}\right)$ that the crystal will be in a single domain state at $H=0$ as when the magnetization is applied along the $c$-axis. However, in the last case the magnetization along the $c$-axis does not change the magnetic structure. The crystal has a gigantic value of the energy product $(\sim 100 \mathrm{mln}$.gauss. Oe $)[1,30]$ and may be used as a permanent magnet at low temperatures.

\section{References}

[1] Deryagin, A. V., Uspechi fiz. nauk 120 (1976) 393.

[2] Clark, A. E., Belson, H. S., Tamagawa, N. and Callen, E., Proc. Int. Conf. Mag. 4 (1974) 335 (Publ. House Nauka, Moscow)

[3] BAJOREK, C. H., Kobliska, R. J., JBM. J. Res. and Develop. 20 (1976) 271.

[4] Onkoshi, M., Kobayashi, H., Katayma, T., Hirano, M., Tsushima, T., Japan. J. Appl. Phys. 15 (1976) 2019.

[5] Kudrevatyke, N. V., Deryagin, A. V., Kazakov, A. A. Reimer, A. V., Moskalev, V. N., Fiz. Met. Metalloved. 45 (1978) 1169.
[6] Tatsumoto E., Okamoto, T., Fuji, H., Inoue, C., J. Physique Colloq. 32 (1971) C1-550; J. Phys. Soc. Japan. 34 (1973) 835.

[7] Deryagin, A. V., Andreev, A. V., Reimer, V. A., JeTF 74 (1978) 1789.

[8] Deryagin, A. V., Kudrevatykh, N. V., Tarasov, E. N., Report on All-Union Conf. Alloys of rare-metals with special properties, Moscow, 1977, in the press.

[9] SChweIzer, J., TASSET, F., Proc. Int. Conf. Mag. 4 (1974) 257 (Publ. House «Nauka », Moscow).

[10] Deryagin, A. V., Kudrevatykh, N. V., Moskalev, V. N., Phys. Status Solidi (a) 45 (1978) 71. 
[11] Deryagin, A. V., Kudrevatykh, N. V., Moskalev, V. N., Fiz. Met. Metalloved. 45 (1978) 718.

[12] Kazakov, A. A., Reimer, V. A., Fiz. Met. Metalloved. 41 (1976) 28

[13] Kazakov, A. A., VINITI No. 3310 (1977) Dep., USSR.

[14] Deryagin, A. V., Kudrevatykh, N. V., Phys. Stat. Sol. (a) 30 (1975) K-129.

[15] Kazakov, A. A., Reimer, V. A., Deryagin, A. V., KudreVATYKH, N. V., Fiz. tverdogo tela 18 (1976) 284.

[16] Carr, W. J., Phys. Rev. 109 (1958) 1971.

[17] Frederick, W. G. D., Hoch, M., IEEE Trans. on Mag. MAG-10 (1974) 733.

[18] Belov, K. P., Zvezdin, A. K., Kadomtseva, A. M., LeviTIN, R. Z., Uspechi fiz. nauk 119 (1976) 447.

[19] Kelarev, B. B., Sidorov, S. K., Pirogov, A. N., VokmmyaNIN, A. P., Pis'ma JETF 26 (1977) 330.

[20] Keller, D. A., Sankar, S. G., Craig, R. S., Wallace, W. E., AIP Conf. Proc. 18 (1973) 1207.
[21] Onoprienko, L. G., Fiz. Met. Metalloved. 17 (1964) 351.

[22] Mitsek, A. I., Kolmakova, N. P., Sirota, D. I., Fiz. Met. Metalloved. 38 (1974) 35.

[23] Melville, D., Khan, W. I., IEEE Trans. on Mag. MAG-12 (1976) 1012.

[24] Derryan, A. V., Baranov, N. V., Abstracts of reports of All-Union Conf. on Physics on magnetic phenomena, Donetsk, 1977, p. 131.

[25] Poldy, C. A., Taylor, K. N. R., J. Phys. F : Metal. Phys. 3 (1973) 145.

[26] Mitsek, A. I., Phys. Stat. Sol. (b) 59 (1973) 309

[27] Deryagin, A. V., Baranov, N. V., To be published.

[28] Gignoux, D., Lemaire, R., Chaissy, J., Proc. Int. Conf. Magn. 5 (1974) 361 (Publ. House " Nauka 》. Moscow).

[29] VAN DEN BROEK, J. J., ZiJlstra, H., IEEE Trans. on Mag. 7 (1971) 226.

[30] Deryagin, A. V., Baranov, N. V., Reimer, V. A., JetF 73 (1977) 1829. 